\title{
Mahua flowers (Madhuca sp.) utilization as a carbon-rich natural substrate for the cost-effective bench-scale production of fumaric acid
}

\author{
Kavita Singh $^{1}$ (D) Deepankar Sharma ${ }^{1} \cdot$ Abha Mishra $^{1}$
}

Received: 20 October 2020 / Accepted: 6 January 2021 / Published online: 11 January 2021

(c) The Author(s) 2021 OPEN

\begin{abstract}
Fumaric acid is a multi-functional bio-based organic acid that is extensively used as a building block compound in chemical synthesis, food preservative and as therapeutics. The substrates required for the production are the sugars that account for $50-60 \%$ of the total process economics. The present work explores the utilization of Mahua flowers as a cheaper carbon source and low cost production medium for cost-effective fumaric acid production using Rhizopus oryzae. Various process parameters for fumaric acid production and desired fungal morphology were investigated, including Mahua flower extract concentration, fermentation temperature, fermentation $\mathrm{pH}$ and agitation speed. The highest concentration of the product, fumaric acid obtained in shake flask was $23.5 \pm 0.9 \mathrm{~g} / \mathrm{L}$ at optimized conditions of $100 \mathrm{~g} / \mathrm{L}$ of Mahua flower extract medium, $\mathrm{pH} 6,30^{\circ} \mathrm{C}$ temperature and shaking speed of $200 \mathrm{rpm}$ in $72 \mathrm{~h}$. The pellet morphology resulted in higher production than mycelial clumps. Bench-scale production in stirred tank reactor resulted in $24.1 \pm 1.0 \mathrm{~g} / \mathrm{L}$ of fumaric acid production at an aeration rate of $1 \mathrm{vvm}$, agitation at $200 \mathrm{rpm}$ and temperature of $30^{\circ} \mathrm{C}$. The results obtained were comparable to fermentation with pure glucose. The present study evidently reveals the feasibility of carbon-rich, low cost, abundantly available natural substrate for cost-effective fumaric acid production.
\end{abstract}

Keywords Mahua flowers · Fumaric acid · Fungal morphology · Process parameter optimization · Bench scale production

\section{Introduction}

Fumaric acid $\left(\mathrm{C}_{4} \mathrm{H}_{4} \mathrm{O}_{4}\right)$ is a natural organic compound possessing diverse applications in various sectors, including the food industry as an acidulant, as a building block chemical for chemical synthesis and as a therapeutic drug. Fumaric acid is produced both by chemical means and by fermentation. The fumaric acid production by chemical process involves utilizing petrochemical derivative maleic anhydride, but the continued rising of petroleum prices and scarcity has sparked an interest in the production of fumaric acid by microbial fermentation [1].

Several Rhizopus $s p$. are able to produce fumaric acid as a product of carbohydrate metabolism under aerobic conditions in $\mathrm{CaCO}_{3}$ containing culture medium [2]. The study on the microbial production of fumaric acid was reported by Erhlrich using Rhizopus nigricans in 1911. Later various species of molds belonging to Mucor, Rhizopus, Cunninghamella and Circinella were recognized as natural fumaric acid producers [3]. Among these genera, the highest concentration of fumaric acid in terms of product yield and volumetric productivity was obtained from Rhizopus species $[2,4]$.

The amount of fumaric acid produced during the fermentation was found to be dependent on the amount of fermentable sugars present in the substrate. To make fumaric acid production process efficient and cost effective through biological means, there is a continuous need

Kavita Singh, kavitas.bce16@itbhu.ac.in |'School of Biochemical Engineering, Indian Institute of Technology (BHU), Varanasi 221005, India. 
to explore novel biomass sources having high carbohydrate content and concomitantly provide essential micro and macro nutrients to serve as cheaper raw material [1]. Variety of cheaper raw materials such as xylose, potato flour, corn starch, molasses, crude glycerol, brewery wastewater and apple pomace have been utilized as cheap carbon source for the fermentative production of fumaric acid [5-11]. The current study deals with the utilization of flowers of Madhuca latifolia that can serve as excellent raw material (carbohydrate rich) for the microbial production of fumaric acid through fermentation.

Madhuca latifolia, commonly known as mahua, is a forest tree abundantly found in India and Australia $[12,13]$. The tree majorly grows in a tropical climate and can easily sustain dry conditions. The tree has been grown in large numbers by the tribal people belonging to India for multifarious activities such as feed for livestock, wood, production of local alcoholic beverage. The yearly productivity of Mahua flowers in India is approximately 2 million tonnes. The flowers from the Mahua tree are an excellent source of carbohydrates and are highly rich in fermentable sugars (glucose, fructose). Moreover, dried Mahua flowers are available as cheap carbon source (US \$ 30-35 ton $^{-1}$ ) in comparison to glucose (US $\$ 400-450$ ton $^{-1}$ ). In view of the light above, the present study explores the dried flowers of Madhuca latifolia as a low-cost production medium for fumaric acid production. The experimental work performed utilizes the Taguchi experimental design for determining the optimum levels of process parameters $(\mathrm{pH}$, temperature and shaking speed) required for maximum production of fumaric acid. The study also reports the changes in fungal morphology observed at different fermentation parameters and their effect on product formation. The utilization of fermentable sugars of Mahua flowers by the fungus Rhizopus oryzae for the production of fumaric acid can be an economically viable process due to the low-cost production medium.

\section{Materials and methods}

\subsection{Materials}

The chemicals utilized in the current study were of analytical grade and procured from Himedia laboratories, Mumbai and standard fumaric acid was purchased from Sigma Aldrich, USA (purity $>99 \%$ ).

\subsubsection{Microorganism}

The fungus Rhizopus oryzae NCIM 877 used in the present study was procured from NCIM repository of National Chemical Laboratory, Pune. The procured strain was grown and maintained on Potato Dextrose Agar slants. The slant cultures were incubated for 4-5 days for the propagation of fungal spores. The mycelial free spores of the fungus Rhizopus oryzae NCIM 877 were obtained by washing the agar slants with sterile water followed by filtering through sterile glass wool. The fungal spore suspension was kept at $4{ }^{\circ} \mathrm{C}$ for subsequent use.

\subsection{Methods}

\subsubsection{Procurement and Pre-treatment of Mahua flowers}

Dried Mahua flowers were procured from the local markets, brought to the Biomolecular Engineering Laboratory of the Institute and washed with the distilled water to remove the dust impurities. The slurry was prepared by pressing $20 \mathrm{gm}$ of Mahua flowers with a mortar and pestle, boiled with $100 \mathrm{ml}$ of distilled water and filtered with a muslin cloth to obtain Mahua flower extract. The filtered residue was resuspended, boiled and filtered in another $100 \mathrm{ml}$ of distilled water. The total volume of Mahua flower extract collected was $200 \mathrm{ml}$. The preparation was further utilized as a natural source of fermentable sugars for submerged fermentation. The total sugars and reducing sugars concentration in Mahua flower extract were estimated using Phenol sulfuric acid and Dinitrosalicylic acid methods respectively $[14,15]$.

\subsubsection{Constituents of preculture medium}

The spore suspension ( $2 \% \mathrm{v} / \mathrm{v})$ was utilized to inoculate the growth medium with the following composition consisted of ( $\mathrm{g} / \mathrm{L}$ ) Mahua flower extract 100, Urea 2, $\mathrm{KH}_{2} \mathrm{PO}_{4}$ $0.6, \mathrm{MgSO}_{4} \cdot 7 \mathrm{H}_{2} \mathrm{O} 0.25, \mathrm{ZnSO}_{4} \cdot 7 \mathrm{H}_{2} \mathrm{O} 0.088$ and $\mathrm{FeSO}_{4} .7 \mathrm{H}_{2} \mathrm{O}$ 0.0088 . The Mahua flower extract was sterilized separately from the rest of the components to prevent the characteristic Maillard reaction between the carbonyl group of reducing sugars and the amino group of urea. The initial set of experiments were carried out at various conditions of $\mathrm{pH}$ ranging from $4-8$, temperature from $25-37{ }^{\circ} \mathrm{C}$ and shaking speed from 100-300 rpm in Mahua flower extract medium to determine the optimum conditions required for the formation of uniform small-sized pellet morphology. The formation of uniform small-sized pellets by the fungus Rhizopus was evaluated as the ideal morphology for the production of fumaric acid as it allows adequate mass transfer of nutrients, oxygen and also prevents the formation of hypoxic conditions [1, 10, 11]. The optimum conditions obtained were then utilized for the cultivation of fungal pellet seed in Erlenmeyer flasks $(250 \mathrm{ml})$ containing $75 \mathrm{ml}$ of growth medium for $24 \mathrm{~h}$. 


\subsubsection{Production medium and implementation of submerged fermentation}

The Mahua flower extract medium was utilized as a carbon source to assess its potential for fumaric acid production. The production medium consisted of $(\mathrm{g} / \mathrm{L})$ Mahua flower extract $100, \mathrm{KH}_{2} \mathrm{PO}_{4} 0.6, \mathrm{MgSO}_{4} .7 \mathrm{H}_{2} \mathrm{O} 0.25, \mathrm{ZnSO}_{4} .7 \mathrm{H}_{2} \mathrm{O}$ 0.088 and $\mathrm{FeSO}_{4} .7 \mathrm{H}_{2} \mathrm{O} 0.0088$ in $1 \mathrm{~L}$ of distilled water. The Rhizopus oryzae grown in a pre-cultured medium was used as a source of inoculum (inoculum size of $10 \% \mathrm{v} / \mathrm{v}$ ) for the submerged fermentation of Mahua flowers and the production was carried out in triplicates. To carry out the fermentation, $180 \mathrm{ml}$ of Mahua flower extract medium was taken in $500 \mathrm{ml}$ Erlenmeyer flasks and inoculated with $20 \mathrm{ml}(10 \% \mathrm{v} / \mathrm{v})$ of pre-cultured Rhizopus oryzae to give a final volume of $200 \mathrm{ml}$ (to impart $55 \mathrm{~g} / \mathrm{L}$ of sugar). Sterile $\mathrm{CaCO}_{3}$ (neutralizing agent) was added to maintain a $\mathrm{pH}$ of 6,7 and 8 whenever required during the course of fermentation.

\subsubsection{Taguchi experimental design}

The effect of the process parameters viz. Temperature, $\mathrm{pH}$ and shaking speed and their optimum conditions were investigated for the fumaric acid production using Taguchi methodology based design of experiments. The experimental design was constructed and statistical analysis was carried out in Minitab 18 software. The three process parameters and their corresponding three levels are depicted in Table 1. L9 orthogonal array was employed and fumaric acid concentration $(\mathrm{g} / \mathrm{L}$ ) was studied as the response. In each experiment, Signal to noise (SN) ratio of "Larger is better" was utilized to analyse the response and also to determine the influence of each process parameter on fumaric acid production. Table 2 depicts the design of experiments utilized and the corresponding Signal to noise $(\mathrm{SN})$ ratios. The generated response table ranks the effects of process parameters on the output and ascertain the levels of the major operating parameters responsible for the process. The results obtained using the Taguchi design led to the determination of the optimal levels of process parameters needed for optimal fumaric acid production. To validate the Taguchi experimental design,

Table 1 Process parameters and their experimental levels

\begin{tabular}{llll}
\hline Level & Temperature $\left({ }^{\circ} \mathrm{C}\right)$ & $\mathrm{pH}$ & $\begin{array}{l}\text { Shaking } \\
\text { speed } \\
\text { (rpm) }\end{array}$ \\
\hline 1 & 25 & 6 & 100 \\
2 & 30 & 7 & 200 \\
3 & 37 & 8 & 300 \\
\hline
\end{tabular}

Table 2 L9 orthogonal array depicting experimental design with $\mathrm{SN}$ ratios

\begin{tabular}{llllll}
\hline S. No & $\begin{array}{l}\text { Tempera- } \\
\text { ture }\left({ }^{\circ} \mathrm{C}\right)\end{array}$ & $\mathrm{pH}$ & $\begin{array}{l}\text { Shaking } \\
\text { speed } \\
(\mathrm{rpm})\end{array}$ & $\begin{array}{l}\text { Fumaric acid } \\
\text { production }(\mathrm{g} / \mathrm{L})\end{array}$ & SN ratio \\
\hline 1 & 25 & 6 & 100 & $13.7 \pm 0.9$ & 22.7344 \\
2 & 25 & 7 & 200 & $9.8 \pm 0.5$ & 19.8245 \\
3 & 25 & 8 & 300 & $6.1 \pm 0.7$ & 15.7066 \\
4 & 30 & 6 & 200 & $23.5 \pm 1.1$ & 27.4214 \\
5 & 30 & 7 & 300 & $11.1 \pm 0.8$ & 20.9065 \\
6 & 30 & 8 & 100 & $8.1 \pm 0.6$ & 18.1697 \\
7 & 37 & 6 & 300 & $9.7 \pm 0.9$ & 19.7354 \\
8 & 37 & 7 & 100 & $5.8 \pm 0.6$ & 15.2686 \\
9 & 37 & 8 & 200 & $5.1 \pm 0.4$ & 14.1514 \\
\hline
\end{tabular}

separate experiments were performed using the combination of optimal levels of process parameters. These experiments were not present in the orthogonal array and were utilized as the validation experiments for the optimum fumaric acid production in shake-flask culture.

\subsubsection{Validation of optimized parameters in bench scale production}

A 3.7 $\mathrm{L}$ stirred reactor (Bioengineering $\mathrm{KLF}$ ) with $2.5 \mathrm{~L}$ processing capacity was utilized to validate optimized process parameters and bench-scale production studies. $\mathrm{CaCO}_{3}$ was utilized as a neutralizing agent to maintain a pH of 6 . Temperature, Aeration rate and agitation were maintained at $30^{\circ} \mathrm{C}, 1 \mathrm{vvm}$ and $200 \mathrm{rpm}$ respectively.

\subsubsection{Fumaric acid recovery and fungal biomass estimation}

The recovery of fumaric acid was performed according to the method described by Das and Brar [10]. The addition of sterile $\mathrm{CaCO}_{3}$ was followed by the formation of insoluble calcium fumarate. The resulting fermented broth was heated to $90{ }^{\circ} \mathrm{C}$ with concomitant acidification $\left(\mathrm{H}_{2} \mathrm{SO}_{4}, 5 \mathrm{~N}\right)$ until clear. The broth was centrifuged $(8000 \times 9,12 \mathrm{~min})$ and the supernatant fraction was then analyzed by spectrophotometer at $460 \mathrm{~nm}$. The concentration of fumaric acid was performed by drying in a rotary dryer. The precipitated fraction containing $\mathrm{CaSO}_{4}$ and fungal biomass was washed and oven-dried until a constant dry weight was obtained.

\subsubsection{Fumaric acid quantification}

Quantification was performed spectrophotometrically, as stated in the method described by Das and Brar [10]. $0.4 \mathrm{ml}$ of broth sample was taken in a test tube and $50 \mu \mathrm{l}$ of copper-pyridyl reagent $\left(\mathrm{CuSO}_{4}+\right.$ pyridine) was added 
resulting in formation of copper-pyridine-fumarate complex. The tubes were cooled at $4{ }^{\circ} \mathrm{C}$, incubated for $15 \mathrm{~min}$ and centrifuged at $2000 \mathrm{rpm}$ for $3 \mathrm{~min}$. To the recovered pellet, $1 \mathrm{ml}$ citric acid solution ( $20 \% \mathrm{w} / \mathrm{v}), 1 \mathrm{ml} \mathrm{NH}_{4} \mathrm{OH}$ solution $(10 \% \mathrm{v} / \mathrm{v}), 200 \mu \mathrm{l}$ gum ghatti solution $(2 \% \mathrm{w} / \mathrm{v})$ and $1 \mathrm{ml}$ of sodium diethyldithiocarbamate solution $(0.2 \% \mathrm{v} / \mathrm{v})$ were added. The resulting solution was quantified spectrophotometrically at $460 \mathrm{~nm}$ due to the formation of a light blue colored fumarate-copper-diethyldithiocarbamate complex. Different concentrations of standard fumaric acid $(100-1000 \mu \mathrm{L})$ were utilized for the preparation of the standard curve.

\subsubsection{Confirmation of fumaric acid production by FT-IR analysis}

The obtained samples were processed and analyzed for FTIR spectra. The analysis was performed on a Thermo Scientific Nicolet iS5 FT-IR spectrophotometer using standard fumaric acid as reference. FT-IR spectra of fumaric acid samples and the reference were recorded in transmittance mode using $\mathrm{KBr}$ approach in the spectral wavenumber region of $4000-400 \mathrm{~cm}^{-1}$.

\section{Results and discussion}

The outcomes obtained from the submerged fermentation studies under various operating parameters confirmed the microbial production of fumaric acid from the flowers of Maduca latifolia by Rhizopus oryzae NCIM 877. The Phenol sulphuric acid method for estimating total sugars and Di-nitro salicylic acid method for estimation of reducing sugars confirmed the presence of $55 \pm 1.5 \% \mathrm{~g} / \mathrm{g}$ of total sugars and $48.5 \pm 1 \% \mathrm{~g} / \mathrm{g}$ of reducing sugars in the substrate after pretreatment. The major fermentable sugars present in the Mahua flower extract were glucose and fructose as confirmed from TLC experiments [13]. The initial experiments performed to determine the operating conditions for obtaining fungal pellets in the Preculture medium led to the inference that the temperature of $30^{\circ} \mathrm{C}$, $\mathrm{pH} 6$ and shaking speed of $200 \mathrm{rpm}$ was ideal for attaining uniform small-sized morphology. This uniform small-sized pellet morphology in seed culture (source of pre-adapted inoculum) was then used to inoculate shake flasks containing production medium incubated at different conditions according to Taguchi experimental design and separate experiments (apart from Taguchi design) to find out the optimum conditions for fumaric acid production and the associated morphology. The various conditions utilized led to different morphological forms and also varying fumaric aid concentration.

\subsection{Optimization of process parameters for production of fumaric acid}

As the optimal production of Fumaric acid is highly dependent on the mycelial morphology, several operating parameters (concentration of fermentable sugars present, the temperature during fermentation, $\mathrm{pH}$, shaking speed) were investigated for Rhizopus oryzae morphology and the product formation in the production medium during submerged fermentation. Pellets formation is the most desirable morphology for industrial production of fumaric acid as pellets provide adequate oxygen and mass transfers, avoiding the wrapping of mycelia in bioreactors, reduction in the viscosity of culture medium and reuse of biomass $[16,17]$.

\subsubsection{Effect of Mahua flower extract medium concentration on fumaric acid production}

Various concentrations of Mahua flower extract medium ranging from $10 \mathrm{~g} / \mathrm{L}$ to $150 \mathrm{~g} / \mathrm{L}$ were tested for both growth of Rhizopus oryzae and fumaric acid production. Mahua flower extract medium was prepared with different concentrations by dissolving a known amount of Mahua flowers in water; boiled and filtered through filter cloth. An increase in biomass was observed with an increase in Mahua flowers concentration in the medium. Fumaric acid concentration showed an increase up to $23.4 \mathrm{~g} / \mathrm{L}$ from $100 \mathrm{~g} / \mathrm{L}$ of Mahua extract medium at fermentation conditions of $\mathrm{pH}$, the temperature of $30^{\circ} \mathrm{C}$, shaking speed of $200 \mathrm{rpm}$ and fermentation time of $72 \mathrm{~h}$. Further increase in the concentration of Mahua flowers greater than $100 \mathrm{~g} / \mathrm{L}$ resulted in increase of biomass dry weight but a decrease in fumaric acid concentration due to the substrate inhibition effect (Fig. 1). The biomass dry weight showed an increase from $1.2 \pm 0.3 \mathrm{~g} / \mathrm{L}$ to $6.5 \pm 0.5 \mathrm{~g} / \mathrm{L}$. The relationship between the fumaric acid concentration and concentration of Mahua flowers lead to the inference that $100 \mathrm{~g} / \mathrm{L}$ of Mahua flower concentration was ideal for the production of fumaric acid.

\subsubsection{Effect of temperature on fungal morphology and product formation}

The analysis of the Taguchi experimental design distinctly indicated that the temperature at level $2\left(30^{\circ} \mathrm{C}\right)$ was optimum for the fumaric acid production by Rhizopus oryzae (Fig. 2). The temperature was ranked as the second most important factor influencing the fumaric acid production as evident from its rank in response tables for SN ratios (Table 3). Moreover, changes in the fermentation temperatures resulted in dissimilarities in the morphological appearances/forms of Rhizopus oryzae NCIM 877. 


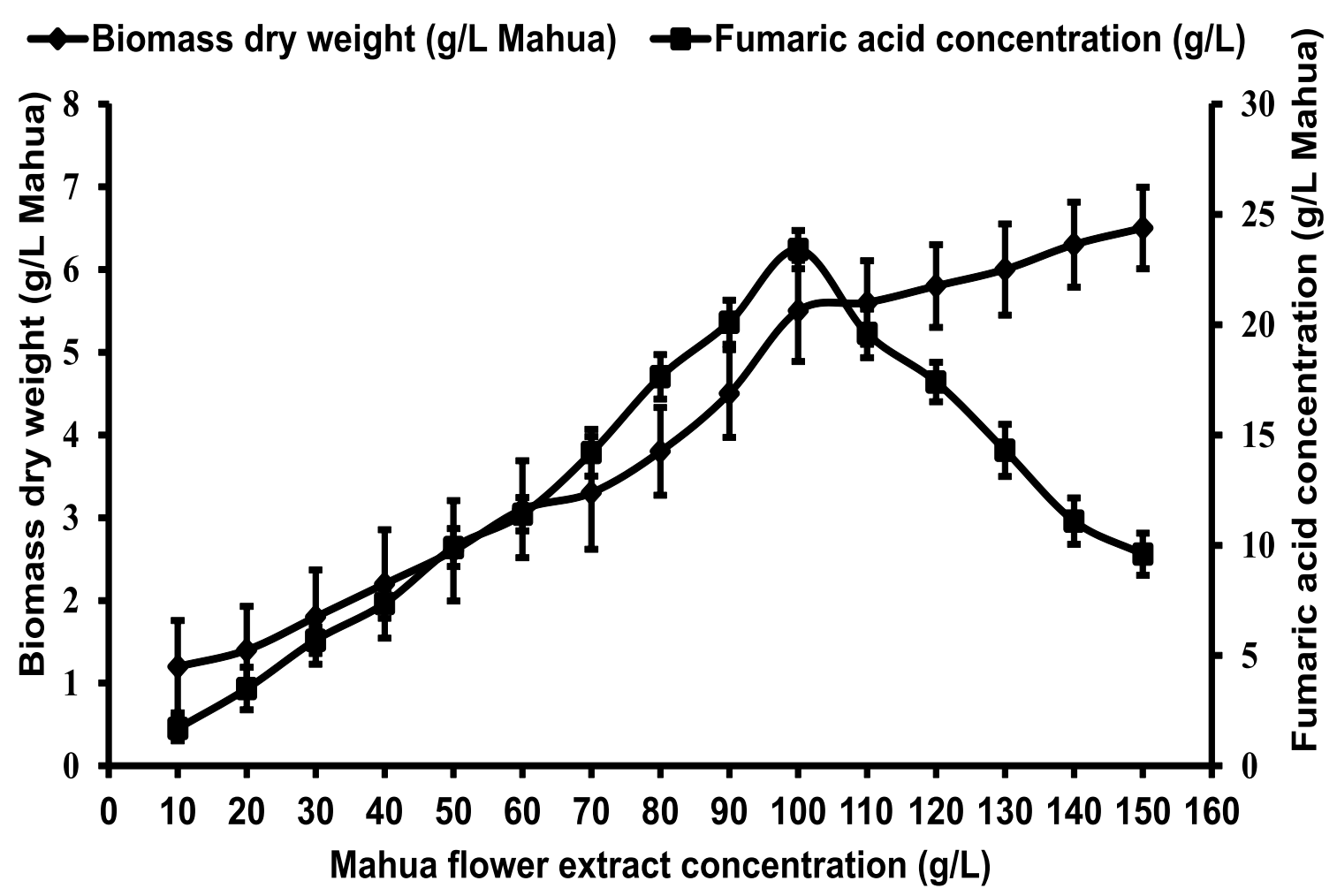

Fig.1 Alterations in growth (Biomass dry weight in $\mathrm{g} / \mathrm{L}$ ) and product formation (Fumaric acid in $\mathrm{g} / \mathrm{L}$ ) with changes in the Mahua flower extract concentration $(\mathrm{g} / \mathrm{L})$

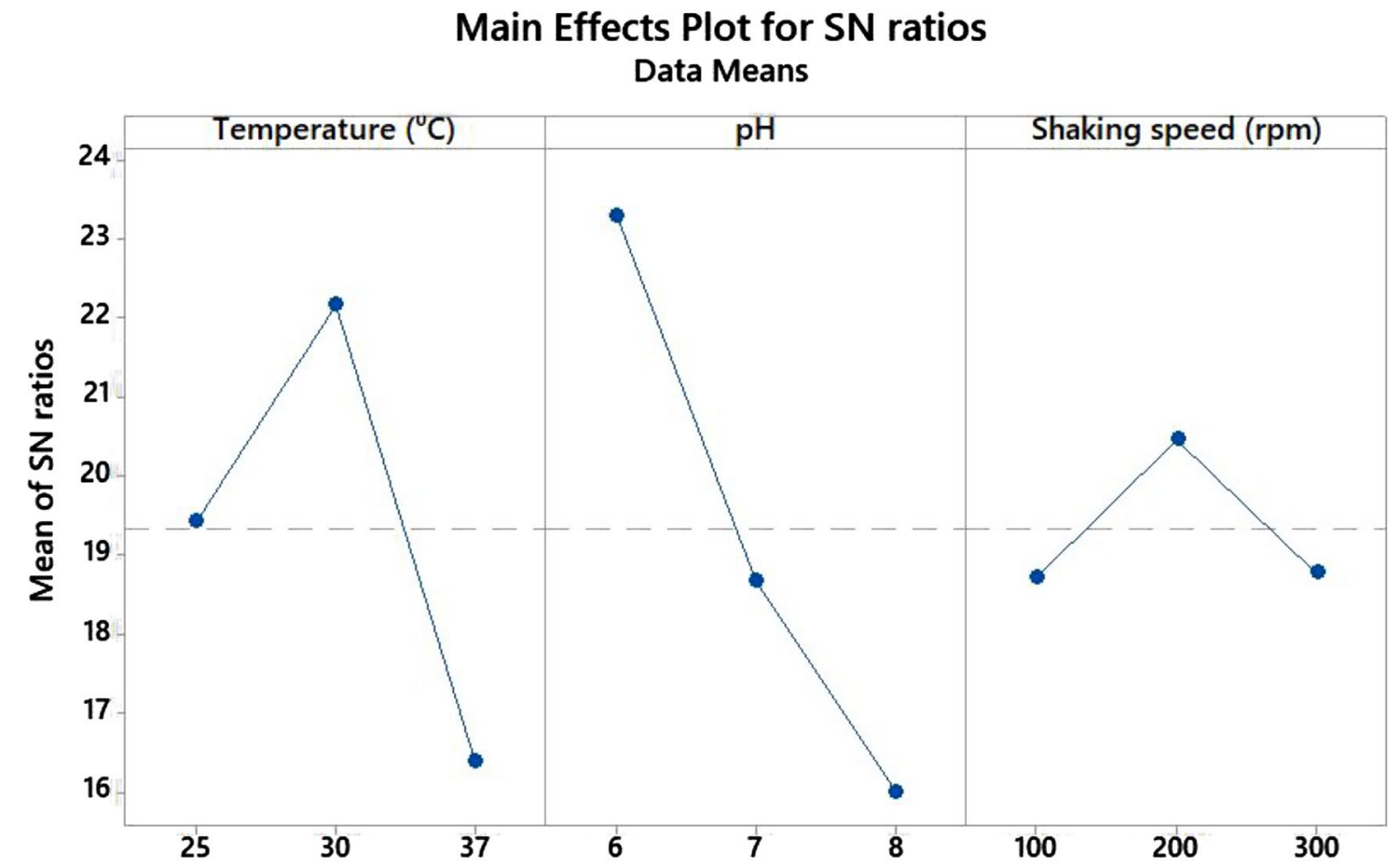

Signal-to-noise: Larger is better

Fig.2 Main effects plots for Signal to noise Ratios depicting optimum levels of process parameters 
Table 3 Response tables for SN ratios depicting ranks and the optimum levels of the process parameters

\begin{tabular}{llll}
\hline Level & Temperature $\left({ }^{\circ} \mathrm{C}\right)$ & $\mathrm{pH}$ & $\begin{array}{l}\text { Shaking } \\
\text { speed } \\
\text { (rpm) }\end{array}$ \\
\hline 1 & 19.42 & 23.30 & 18.72 \\
2 & 22.17 & 18.67 & 20.47 \\
3 & 16.39 & 16.01 & 18.78 \\
Delta & 5.78 & 7.29 & 1.74 \\
Rank & 2 & 1 & 3 \\
\hline
\end{tabular}

Small-sized uniform pellets appeared at $30^{\circ} \mathrm{C}$, as shown in Fig. 3b. Large pellets were formed at $25^{\circ} \mathrm{C}$ and suspended mycelia were observed at $37^{\circ} \mathrm{C}$ (Fig. $3 \mathrm{a}, \mathrm{C}$ ). Both $25^{\circ} \mathrm{C}$ and $37^{\circ} \mathrm{C}$ resulted in lesser fumaric acid formation with concentrations of $12.7 \pm 0.9 \mathrm{~g} / \mathrm{L}$ and $10.1 \pm 0.8 \mathrm{~g} / \mathrm{L}$ respectively in comparison to $23.3 \pm 0.7 \mathrm{~g} / \mathrm{L}$ of fumaric acid formed at $30^{\circ} \mathrm{C}$ (Fig. 3d). For optimum production of fumaric acid, pellet morphology with small pellets was found to be more suitable than large size pellets and suspended mycelia. The explanation for higher production at $30^{\circ} \mathrm{C}$ was the formation of small pellets that allowed undisturbed transfer of mass and oxygen during the fermentation. Large pellets resulted in the formation of hypoxic conditions and the existence of non-viability regions inside the core of the pellets $[18,19]$. As the fumaric acid formation is a highly aerobic process, small pellets are desirable as they do not allow the formation of hypoxic zones and side products thereby resulting in efficient formation of fumaric acid [20]. In one study, it was proposed that the transformation of fungal pellets to suspended mycelia was due to insufficient oxygen supply to the culture [11].

\subsubsection{Effect of $\mathrm{pH}$ variation on fungal morphology and fumaric acid production}

Variations in the $\mathrm{pH}$ values also influenced the fumaric acid production and led to the formation of different morphological forms of Rhizopus oryzae. The results obtained from the response tables for $\mathrm{SN}$ ratios distinctly demonstrated that $\mathrm{pH}$ is most influential factor responsible for
Fig. 3 Variations in the morphological forms of Rhizopus oryzae NCIM 877 observed at different incubation temperatures (a) Large pellets at $25^{\circ} \mathrm{C}$ (b) Small-sized uniform pellets at $30^{\circ} \mathrm{C}$ (c) Suspended mycelia at $37^{\circ} \mathrm{C}$ (d) fumaric acid production profile at different temperature conditions (a)

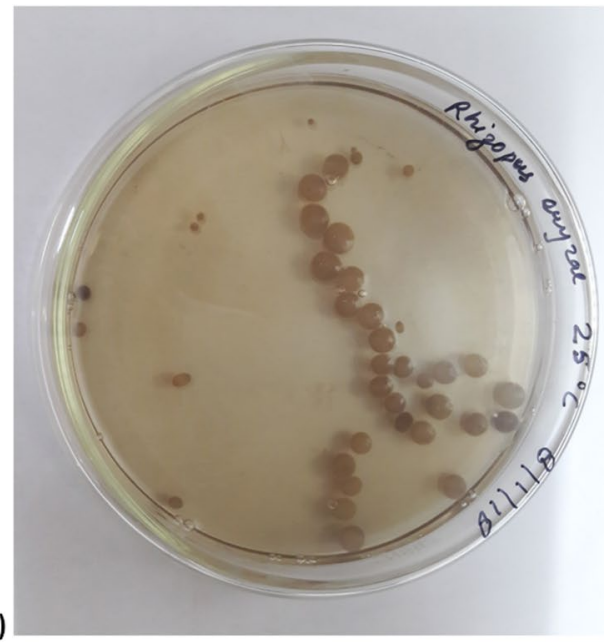

(b)

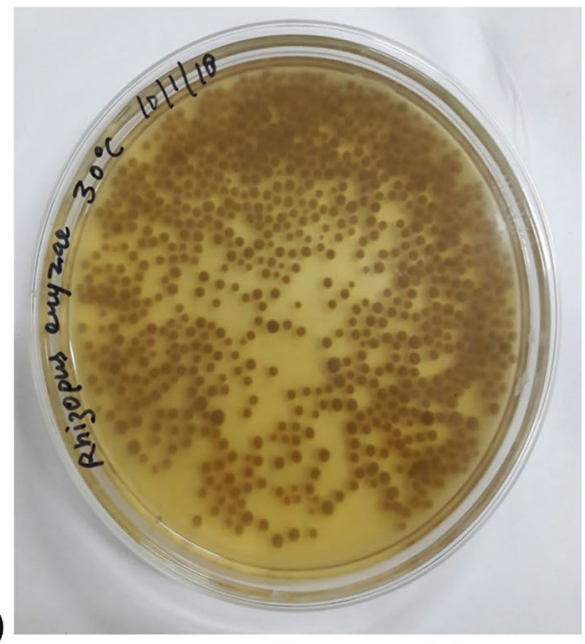

(c)

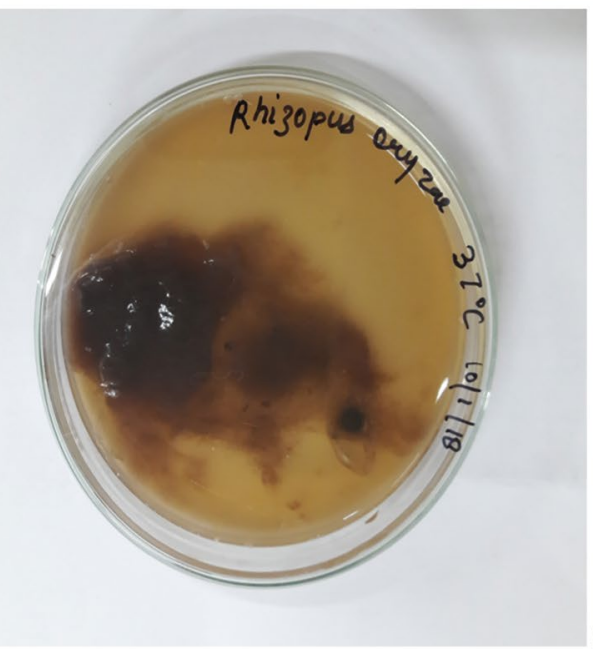

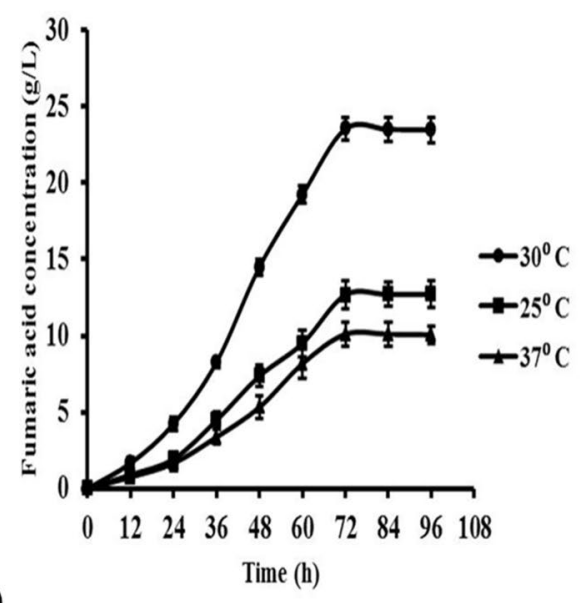


the fumaric acid production process. The highest rank obtained in both the response tables and Analysis of Variance (ANOVA) studies distinctly demonstrate it as the most crucial factor influencing the process (Tables 3 and 4). The level 1 ( $\mathrm{pH}$ 6) was observed as the optimum $\mathrm{pH}$ favouring the production of fumaric acid as depicted by Fig. 2 . The $\mathrm{pH}$ value of 6 resulted in the formation of small size pellets that are more conducive for efficient transfer of mass and oxygen (Fig. 4a). The $\mathrm{pH}$ value of 7 is accompanied by mixed morphology (mycelia and pellets) and $\mathrm{pH} 8$ resulted in the formation of mycelia clumps (Fig. 4b, c). These morphological forms of suspended mycelia and larger pellets suffer from the drawbacks of insufficient transfer of oxygen and nutrients inside the core regions resulting in the creation of hypoxic conditions which therefore hamper and alter the productivity of Rhizopus oryzae to form fumaric acid. The fumaric acid production attained a concentration of up to $23.3 \pm 1.0 \mathrm{~g} / \mathrm{L}$ at $\mathrm{pH}$ 6. In contrast, the $\mathrm{pH}$ values of 7 and 8 resulted in production of $8.4 \pm 0.6 \mathrm{~g} / \mathrm{L}$ and $6.8 \pm 1.2 \mathrm{~g} / \mathrm{L}$ of fumaric acid respectively (Fig. $4 \mathrm{~d}$ ).

\subsubsection{Effect of shaking speed variations on fungal morphology and product formation}

Alterations in the flask shaking speeds also lead to subtle differences in the morphology of Rhizopus oryzae.
Table 4 Analysis of variance for $\mathrm{SN}$ ratios of fumaric acid production

\begin{tabular}{llrrrrr}
\hline Source & DF & \multicolumn{1}{c}{ Seq SS } & \multicolumn{1}{c}{ Adj SS } & Adj MS & \multicolumn{1}{c}{ F } & P \\
\hline Temperature & 2 & 50.168 & 50.1667 & 25.0838 & 554.87 & 0.002 \\
pH & 2 & 78.405 & 81.6157 & 40.8078 & 902.69 & 0.001 \\
Shaking speed & 2 & 5.869 & 5.8686 & 2.9343 & 64.91 & 0.015 \\
Residual error & 2 & 0.090 & 0.0904 & 0.0452 & & \\
Total & 8 & 137.742 & & & & \\
\hline
\end{tabular}

Fig. 4 Variations in the different types of morphologies formed by Rhizopus oryzae NCIM 877 at different $\mathrm{pH}$ conditions (a) small size pellets at $\mathrm{pH} 6$ (b) mixed morphology (mycelia and pellets) at $\mathrm{pH} 7$ (c) mycelia clumps at $\mathrm{pH} 8$ (d) fumaric acid production profile at various $\mathrm{pH}$ conditions (a)
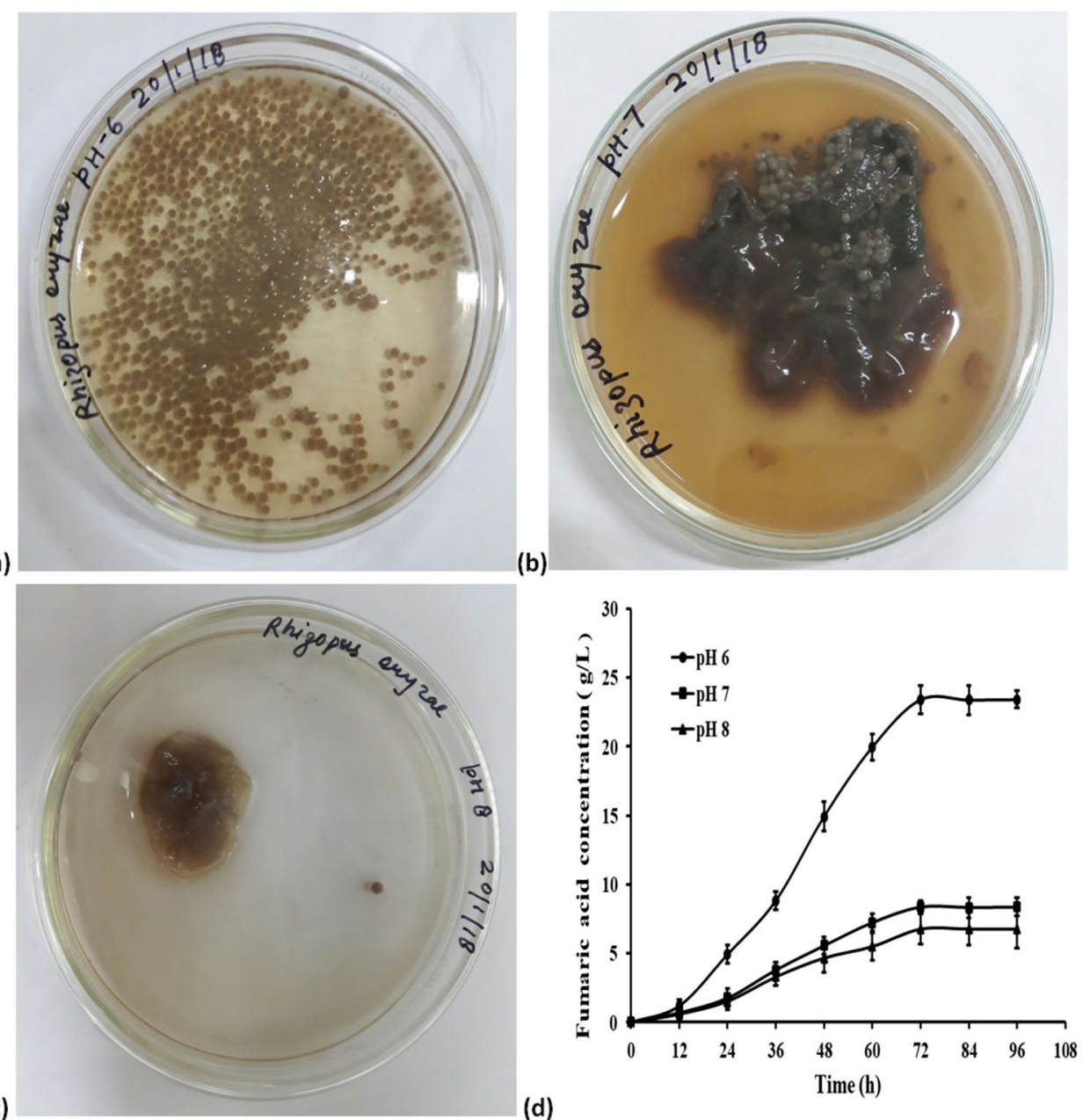
The shaking of culture flasks was performed at $100 \mathrm{rpm}$, $200 \mathrm{rpm}$ and $300 \mathrm{rpm}$ speeds to observe fumaric acid production under these conditions. Among the three major factors, shaking speed was ranked third in affecting the production of fumaric acid (Table 3$)$. The level 2 (200 rpm) was recognized as the optimum condition in the main effects plot for $\mathrm{SN}$ ratio (Fig. 2). Variation in rpm speeds leads to the generation of hydrodynamic force which will directly influence the morphology of the fungus. Suspended mycelial morphology was observed at $100 \mathrm{rpm}$ speed, as shown in Fig. 5a resulting in the production of $13.1 \pm 1.1 \mathrm{~g} / \mathrm{L}$ fumaric acid (Fig. $5 \mathrm{~d}$ ). Small and uniform size pellets were seen at $200 \mathrm{rpm}$ speed, as depicted by Fig. $5 \mathrm{~b}$ with fumaric acid production of $22.6 \pm 1.2 \mathrm{~g} / \mathrm{L}$ (Fig. $5 \mathrm{~d}$ ). A further rise in shaking speeds from 200 to $300 \mathrm{rpm}$ ensued in the formation of large pellets as seen in Fig. $5 c$ with fumaric acid production of $16.4 \pm 1.3 \mathrm{~g} / \mathrm{L}$ (Fig. $5 \mathrm{~d}$ ). The explanation for the formation of the mycelial morphology was that the initial pellets formed later agglomerated to form dense mycelia resulting in the formation of hypoxic zones and lower productivity from the fungus. At a medium range of rpm levels (200 rpm), no clumping or aggregation of pellets occurred, resulting in enhanced production of fumaric acid.

\subsection{Fumaric acid production under optimized conditions}

The fungus showed excellent growth and favorable metabolic activities for the formation of fumaric acid. The concentration of fumaric acid achieved in shake flask studies was $23.5 \pm 0.9 \mathrm{~g} / \mathrm{L}$. Slight enhancement in yield was observed in fermentor studies with fumaric acid production of $24.1 \pm 1.0 \mathrm{~g} / \mathrm{L}$ under optimized parameters $(100 \mathrm{~g} / \mathrm{L}$ of Mahua flower extract medium providing $55 \pm 1.5 \mathrm{~g} / \mathrm{L}$ of total fermentable sugars, $\mathrm{pH} 6,30^{\circ} \mathrm{C}$ temperature, shaking speed of $200 \mathrm{rpm}$ ) as shown in Fig. 6a. When pure glucose was utilized as a carbon source $(55 \mathrm{~g} / \mathrm{L}), 24.9 \pm 0.5 \mathrm{~g} / \mathrm{L}$ of fumaric acid was produced (Fig. 6b). The results obtained using Mahua flowers as carbon source were slightly lesser but comparable $(24.1 \pm 1.0 \mathrm{~g} / \mathrm{L})$ due to the complex nature of the substrate. Upon productivity comparison, the volumetric productivity achieved in the present study of $0.334 \mathrm{~g} /(\mathrm{L} \mathrm{h})$ using Mahua flowers was comparable to
Fig. 5 Variation in the morphology of Rhizopus oryzae NCIM 877 observed due to the alterations in the flask shaking speeds (a) Mycelial morphology at 100 rpm (b) Small and uniform size pellets at $200 \mathrm{rpm}$ (c) Large pellets at $300 \mathrm{rpm}$ (d) fumaric acid production profile at different shaking speeds utilized during study (a)

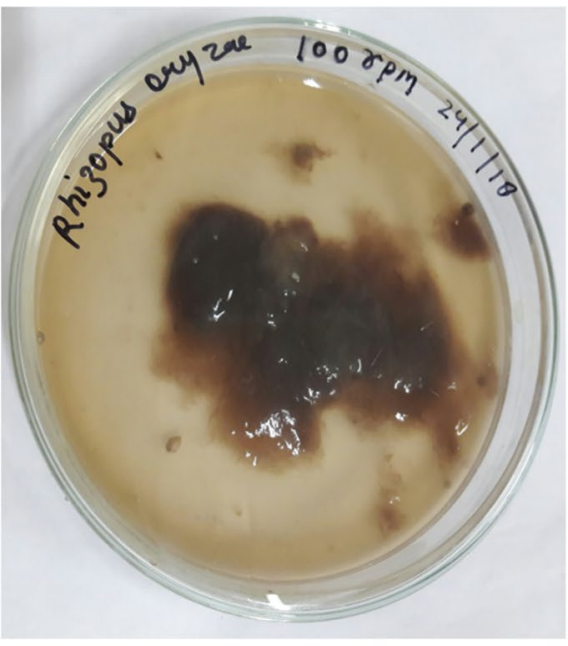

(b)

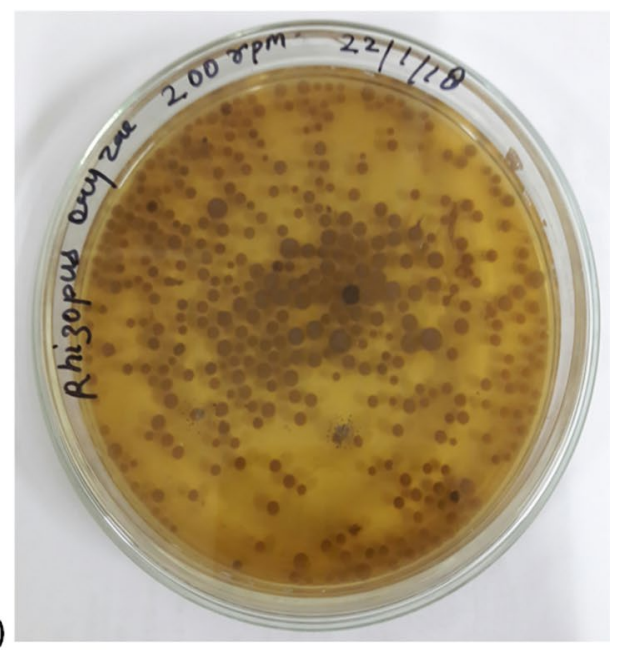

(c)

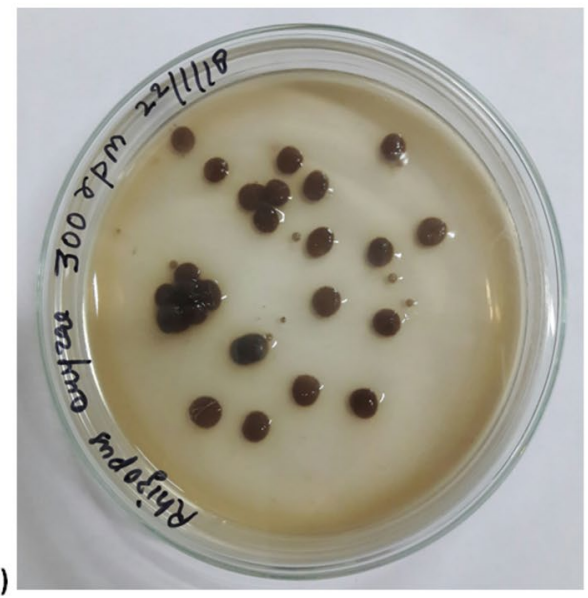

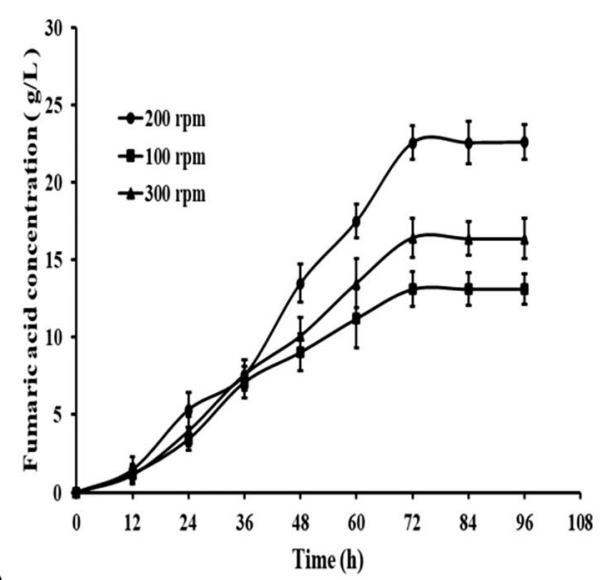




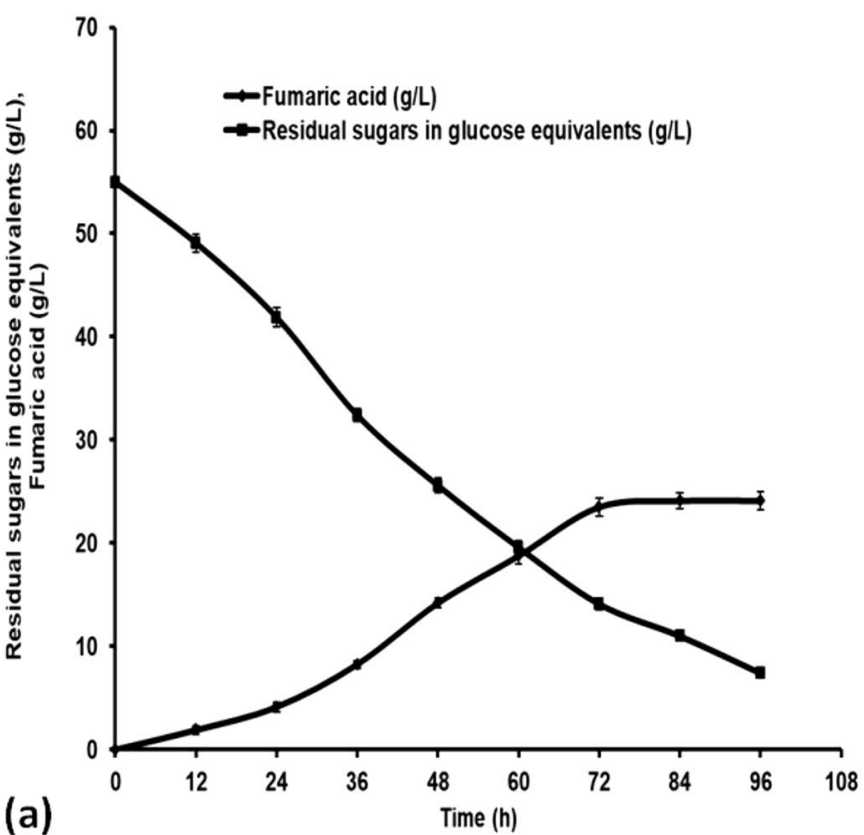

Fig. 6 Substrate utilization profiles of (a) Mahua flowers (residual sugars in glucose equivalents), (b) pure glucose and product formation profiles (fumaric acid) by Rhizopus oryzae NCIM 877 under

productivity of $0.345 \mathrm{~g} /(\mathrm{L} \mathrm{h})$ using pure glucose. The outcomes inferred from the experiments conclude that the extremely low priced, abundantly available and carbon rich Mahua flowers can serve as an excellent cost-effective carbon source for the microbial production of fumaric acid through the fermentation process.

IR spectra of fumaric acid sample and standard (Fig. 7) confirmed the chemical structure and microbial

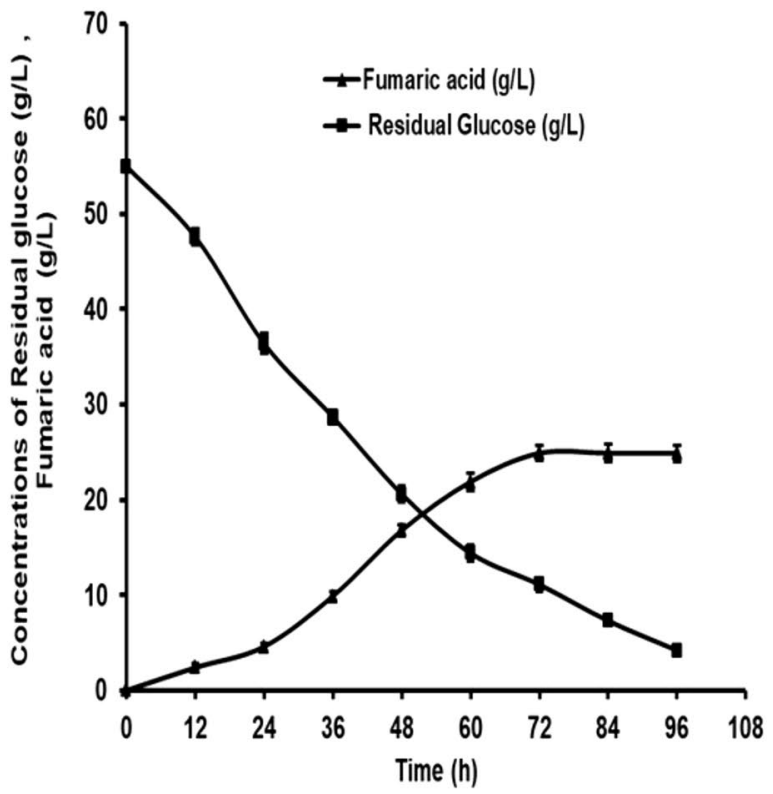

(b)

optimized conditions in a laboratory scale fermentor at $\mathrm{pH}$ of 6 temperature of $30^{\circ} \mathrm{C}$ and agitation of $200 \mathrm{rpm}$

production using Mahua flower extract medium. The carbonyl group $(C=0)$ stretch of fumaric acid was observed as strong bands at $1800-1600 \mathrm{~cm}^{-1}$, the stretching vibrations of the hydroxyl group was observed as wide bands at $3300-2800 \mathrm{~cm}^{-1}$. All the peaks and stretches observed in IR spectra clearly define that the fumaric acid sample and the standard have no differences. All the functional groups are present in native form compared with the standard.
Fig. 7 IR spectra of fumaric acid production sample and standard fumaric acid

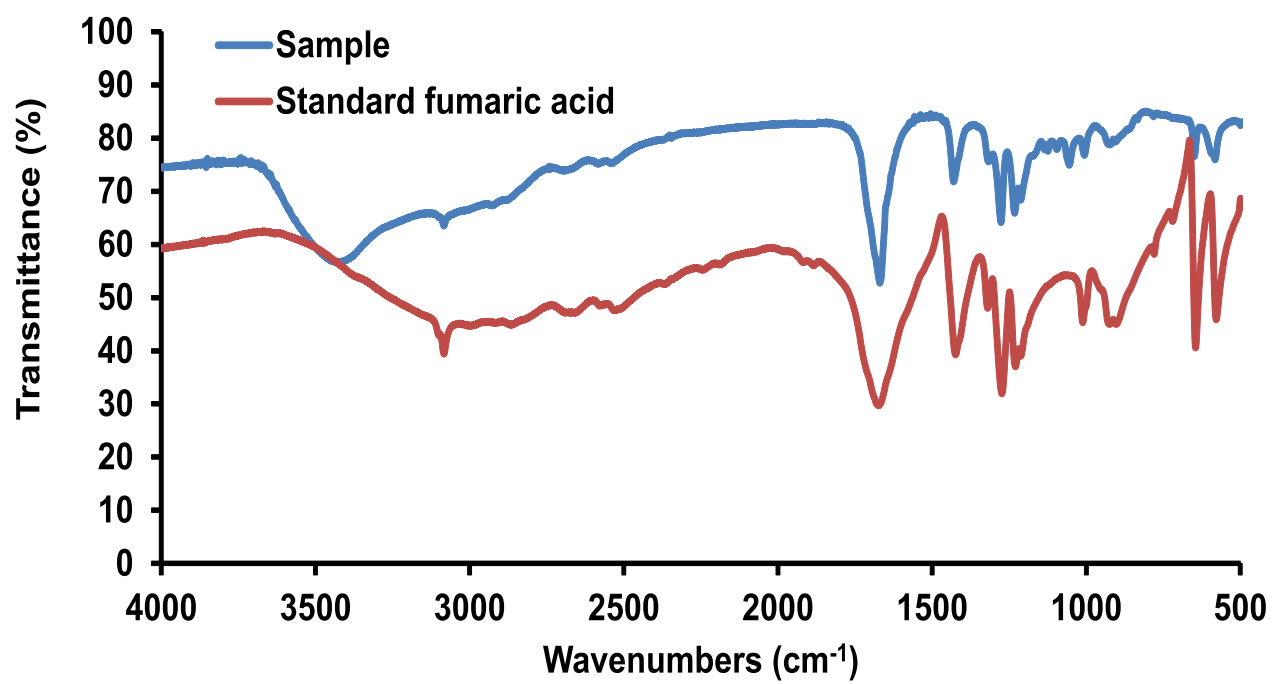

SN Applied Sciences 


\section{Conclusion}

The major cost factor responsible for the fumaric acid production process is the utilization of commercial carbon sources which are expensive. The reduction in the production cost can be done using natural carbon rich cheaper substrates. In the present research study, dried flowers of Madhuca latifolia were utilized for the production of fumaric acid. The sugars present in the Mahua flowers served as excellent substrates for the growth and the formation of fumaric acid by the fungus Rhizopus oryzae. The fumaric acid production using Mahua ( $24.1 \pm 1.0 \mathrm{~g} / \mathrm{L}$ ) was comparable to the fumaric acid obtained from Glucose. The present study evidently reveals the feasibility of low-cost natural substrate for cost-effective fumaric acid production using Rhizopus oryzae.

Acknowledgements We thank School of Biochemical engineering, Indian Institute of Technology BHU Varanasi, India for providing us the infrastructure and facilities for conducting research work.

Author contributions All authors contributed to the study conception and design. Material preparation, data collection and analysis were performed by Kavita Singh, Deepankar Sharma and Abha Mishra. The first draft of the manuscript was written by Kavita Singh and all authors commented on previous versions of the manuscript. All authors read and approved the final manuscript.

\section{Compliance with Ethical Standards}

Competing interests The authors have no conflicts of interest to declare that are relevant to the content of this article.

Open Access This article is licensed under a Creative Commons Attribution 4.0 International License, which permits use, sharing, adaptation, distribution and reproduction in any medium or format, as long as you give appropriate credit to the original author(s) and the source, provide a link to the Creative Commons licence, and indicate if changes were made. The images or other third party material in this article are included in the article's Creative Commons licence, unless indicated otherwise in a credit line to the material. If material is not included in the article's Creative Commons licence and your intended use is not permitted by statutory regulation or exceeds the permitted use, you will need to obtain permission directly from the copyright holder. To view a copy of this licence, visit http://creativecommons .org/licenses/by/4.0/.

\section{References}

1. Engel CAR, Straathof AJJ, Zijlmans TW, van Gulik WM, van der Wielen LAM (2008) Fumaric acid production by fermentation. Appl Biochem Biotechnol 78:379-389. https://doi.org/10.1007/ s00253-007-1341-X

2. Carta FS, Soccol CR, Ramos LP, Fontana JD (1999) Production of fumaric acid by fermentation of enzymatic hydrolysates derived from cassava bagasse. Bioresour Technol 68:23-28. https://doi. org/10.1016/S0960-8524(98)00074-1
3. Foster JW, Waksman SA (1939) The production of fumaric acid by molds belonging to the genus Rhizopus. J Am Chem Soc 61:127-135. https://doi.org/10.1021/ja01870a043

4. Cao N, Du J, Gong CS, Tsao GT (1996) Simultaneous Production and Recovery of Fumaric Acid from Immobilized Rhizopus oryzae with a Rotary Biofilm Contactor and an Adsorption Column. Appl Environ Microbiol 62:2926-2931. https://doi.org/10.1128/ aem.62.8.2926-2931.1996

5. Kautola H, Linko Y-Y (1989) Fumaric acid production from xylose by immobilized Rhizopus arrhizus cells. Appl Microbiol Biotechnol 31:448-452. https://doi.org/10.1007/BF00270774

6. Moresi M, Parente E, Petruccioli M, Federici F (1991) Optimization of fumaric acid production from potato flour by Rhizopus arrhizus. Appl Microbiol Biotechnol 36:35-39. https://doi. org/10.1007/BF00164695

7. Moresi M, Parente E, Petruccioli M, Federici F (1992) Fumaric acid production from hydrolysates of starch-based substrates. J Chem Technol Biotechnol 54:283-290. https://doi.org/10.1002/ jctb. 280540312

8. Petruccioli M, Angiani E, Federici F (1996) Semi-continuous fumaric acid production by Rhizopus arrhizus immobilized in polyurethane sponge. Process Biochem 31:463-469. https://doi. org/10.1016/0032-9592(95)00089-5

9. Zhou Y, Nie K, Zhang X, Liu S, Wang M, Deng L, Wang F, Tan T (2014) Production of fumaric acid from biodiesel-derived crude glycerol by Rhizopus arrhizus. Bioresour Technol 163:48-53. https://doi.org/10.1016/j.biortech.2014.04.021

10. Das RK, Brar SK (2014) Enhanced fumaric acid production from brewery wastewater and insight into the morphology of Rhizopus oryzae 1526. Appl Biochem Biotechnol 172:2974-2988. https://doi.org/10.1007/s12010-014-0739-z

11. Das RK, Brar SK, Verma M (2015) A fermentative approach towards optimizing directed biosynthesis of fumaric acid by Rhizopus oryzae 1526 utilizing apple industry waste biomass. Fungal Biol 119:1279-1290. https://doi.org/10.1016/j.funbi o.2015.10.001

12. Kumar PKA, Shamala TR, Kshama L, Prakash M, Joshi G, Chandrashekar A, Kumari KSL, Divyashree MS (2007) Bacterial synthesis of poly (hydroxybutyrate-co-hydroxyvalerate) using carbohydrate-rich mahua (Madhuca sp.) flowers. J Appl Microbiol 103:204-209. https://doi.org/10.1111/j.1365-2672.2006.03221.x

13. Swain MR, Kar S, Sahoo AK, Ray RC (2007) Ethanol fermentation of mahula (Madhuca latifolia L.) flowers using free and immobilized yeast Saccharomyces cerevisiae. Microbiol Res 162:93-98. https://doi.org/10.1016/j.micres.2006.01.009

14. Dubois M, Gilles KA, Hamilton JK, Rebers PA, Smith F (1956) Colorimetric method for determination of sugars and related substances. Anal Chem 28:350-356. https://doi.org/10.1021/ ac60111a017

15. Miller GL (1959) Use of dinitrosalicylic acid reagent for determination of reducing sugar. Anal Chem 31:426-428. https://doi. org/10.1021/ac60147a030

16. Porcel EMR, López JLC, Pérez JAS, Sevilla JMF, Chisti Y (2005) Effects of pellet morphology on broth rheology in fermentations of Aspergillus terreus. Biochem Eng J 26:139-144. https://doi. org/10.1016/j.bej.2005.04.011

17. Tixier N, Guibaud G, Baudu M (2003) Determination of some rheological parameters for the characterization of activated sludge. Bioresour Technol 90:215-220. https://doi.org/10.1016/ S0960-8524(03)00109-3

18. Zhou Y, Du J, Tsao GT (2000) Mycelial pellet formation by Rhizopus oryzae ATCC 20344. Appl Biochem Biotechnol 84:779-789. https://doi.org/10.1385/ABAB:84-86:1-9:779

19. Zhou Z, Du G, Hua Z, Zhou J, Chen J (2011) Optimization of fumaric acid production by Rhizopus delemar based on the 
morphology formation. Bioresour Technol 102:9345-9349. https ://doi.org/10.1016/j.biortech.2011.07.120

20. Papagianni M (2004) Fungal morphology and metabolite production in submerged mycelial processes. Biotechnol Adv 22:189-259. https://doi.org/10.1016/j.biotechadv.2003.09.005
Publisher's Note Springer Nature remains neutral with regard to jurisdictional claims in published maps and institutional affiliations. 